\title{
Article \\ Self-Correcting Virtual Current Sensor Based on the Modified Luenberger Observer for Fault-Tolerant Induction Motor Drive
}

\author{
Michal Adamczyk (D) and Teresa Orlowska-Kowalska *(D) \\ Department of Electrical Machines, Drives and Measurements, Wroclaw University of Science and Technology, \\ Wybrzeze Wyspianskiego 27, 50-370 Wroclaw, Poland; michal.adamczyk@pwr.edu.pl \\ * Correspondence: teresa.orlowska-kowalska@pwr.edu.pl; Tel.: +48-71-320-2640
}

Citation: Adamczyk, M.; Orlowska-Kowalska, T.

Self-Correcting Virtual Current

Sensor Based on the Modified

Luenberger Observer for

Fault-Tolerant Induction Motor Drive.

Energies 2021, 14, 6767. https://

doi.org/10.3390/en14206767

Academic Editors: Frantisek Durovsky and Pavol Makys

Received: 27 September 2021

Accepted: 13 October 2021

Published: 17 October 2021

Publisher's Note: MDPI stays neutral with regard to jurisdictional claims in published maps and institutional affiliations.

Copyright: (c) 2021 by the authors. Licensee MDPI, Basel, Switzerland. This article is an open access article distributed under the terms and conditions of the Creative Commons Attribution (CC BY) license (https:// creativecommons.org/licenses/by/ $4.0 /)$.

\begin{abstract}
Fault-tolerant control (FTC) solutions are increasingly being used in modern drive systems with AC motors. Such systems provide a higher degree of security and solutions that allow the on-line detection and localization of failures, as well as the switching of the control mode to a mode that allows us to continue the operation or safely stop the drive system. As the current sensors (CSs) are necessary to ensure precise control of the AC motors, in the event of their failure, one of two strategies can be used-hardware or software redundancy. The first strategy requires the use of additional measuring sensors. For this reason, the algorithmic solution, based on the Luenberger Observer (LO), has been proposed in this article as one of the software redundancy methods. In contrast to methods presented in the literature, the proposed solution allows one not only to compensate the stator current in a phase with a faulty CS, but also to adjust the correction of current estimation based on a measured signal in the other phase with a healthy CS. Extensive simulation studies in the direct rotor flux-oriented control (DRFOC) structure with the induction motor (IM) confirm the effectiveness of the proposed method. In addition, the proposed solution allows the drive system to be controlled even if all CSs are damaged.
\end{abstract}

Keywords: induction motor; fault-tolerant control; direct rotor flux-oriented control; current sensorless; Luenberger observer

\section{Introduction}

Induction motor (IM) drive systems are increasingly being used in industrial and communication applications. Particularly noteworthy is the fact that, especially in the powertrains of different transportation vehicles, apart from synchronous motors with permanent magnets (PMSM), they are an alternative to gasoline engines, due to their much lower mechanical complexity (thus greater reliability), higher efficiency, low cost, and no emission of harmful substances during operation. Despite the above advantages, it should be remembered that damage can also occur in the IM, among which the most common are those related to bearings, stator windings, and a rotor [1]. In addition, ensuring precise speed control of the IM requires the use of complex vector control techniques, such as direct torque control (DTC) or direct field-oriented control (DFOC) [2,3]. The practical implementation of these control methods requires the use of devices also susceptible to failure, such as frequency converters $[4,5]$ and appropriate measuring equipment, including current and voltage sensors, rotor speed, or position sensors [6,7].

Accurate determination of the actual value of the stator current is necessary to use effectively the vector control techniques of IMs. For this purpose, noninvasive LEM current transducers are often used. The conductor through which the primary current flows is placed in the core with the Hall-effect sensor in the slot. The magnetic flux generated by the primary current causes the Hall sensor and the associated electronic circuit to generate a compensating current corresponding to the instantaneous value of the primary current. Then, the voltage drop across the appropriately selected output resistor, proportional to 
the primary current, is measured and fed to the digital circuit. In order to determine the characteristics of a current transducer, a series of measurements of the voltage drop across the output resistor should be carried out for different values of the primary current, and then their linear approximation should be made.

Current sensor (CS) faults in the drive systems are one of the most frequent failures among measuring apparatus [7,8]. Due to their structure, six types of damage can be distinguished [9]:

1. Gain change: it can be caused by a change in the resistance of the output resistor, so the output voltage is $n$ times greater than the approximation function;

2. Offset: it results from inaccurate crossing of the approximation function through the zero point;

3. Noise: it results from the accuracy of LEM-type transducers or external disturbances and, in most cases, it does not prevent the system from working;

4. Saturation: it is created by saturation of the magnetic core;

5. Open circuit: complete disappearance of the output signal;

6. Intermittent disconnection of the circuit: it causes momentary output signal fading.

The two latter failures especially are most critical to the drive system, as they prevent the control structure from operating.

CS failure compensation requires the use of one of two active fault-tolerant control (FTC) strategies: hardware redundancy or software redundancy [7]. In the case of the first solution, redundancy of the measuring devices should be used. The use of three CSs allows one to take advantage of the three-phase symmetry of the IM and to determine one of the phase currents in the case of one CS fault on the basis of the other two. However, in the case of industrial drive systems, the most common is the use of CSs only in two motor phases, as the information on minimum two-phase currents is required in the AC drive systems to allow the phase quantities to be transformed into the rectangular coordinate system used in the vector control structure. It is also possible to completely abandon the measurement of phase currents and use only one current sensor (or shunt resistor) in the DC bus of the voltage source inverter (VSI), as it was proposed in $[10,11]$. This solution, however, brings some problems with the appropriate mapping of the phase currents, which may be associated with maximum speed limitations, electromagnetic torque and current ripples [12], or the need to modify the connections of IGBT transistors [13], particularly in the low range of the angular speed. For this reason, these solutions are more often targeted at low-cost systems.

Software redundancy is based on algorithmic solutions. In the case when damage causes an amplification error, the asymmetry index can be used, thanks to which it is possible to detect and locate the damaged CS [14]. The advantage of this approach is that there is no need to use mathematical models, which makes the algorithm insensitive to changes in IM parameters. Unfortunately, this solution is not able to compensate for the complete loss of information about the actual value of the phase current.

In the event of more serious damage to the CS (lack or disappearance of the signal), it is possible to apply solutions based on an appropriate transformation of the coordinate system. In [15], it was proposed to use the stator current reference signals in the rotating coordinate system $(d-q)$, when only the current in phase $A$ or $B$ can be measured. However, the article presented test results in steady states only. The advantage of this method is also the insensitivity to changes in IM parameters; however, this solution does not allow for maintaining such high control precision as in the case of a system with two CSs.

Other approaches found in the literature are based on the use of stator current estimators of the IM. These solutions have become very popular in recent years [8,16-19]. In [8], the other CS fault compensator based on the flux-linkage observer was used; however, the authors paid attention to its significant sensitivity to IM parameters. The VCS algorithm proposed in [16] can be used to compensate for damage to all CSs in the IM drive. As it is most sensitive to changes in the rotor resistance, the method for the compensation of the IM operating point to this parameter is presented in [19]. This method allowed 
one to significantly increase the quality of the stator current estimation. The Luenberger Observer (LO) can also be used to estimate the stator current, as shown in $[17,18]$. However, the authors used the characteristic parameter $k_{0}$ of the observer gain matrix close to 1 , making elements of this matrix close to 0 , which caused the feedback term of the observer to practically disappear.

This article proposed a modified LO for the estimation of the stator current in the case of CS failure in phase $A$ or $B$ of the DRFOC drive system with the IM. Three variants of the stator current error applied in the LO mathematical model were proposed, which enable the proper reconstruction of the current in the stator winding phase with faulty CSs. Moreover, the algorithm is able to reconstruct the phase currents even in the case of the complete lack of information about the measured stator current values. Extensive research was carried out on the influence of the design factor in the LO gain matrix and the form of the current error feedback on the quality of the stator current estimation in the drive system with faulty CSs.

\section{Induction Motor Drive System}

\subsection{Mathematical Model of the Induction Motor}

The implementation of the induction motor mathematical model requires the application of appropriate simplifications presented, among others, in $[3,20]$. With these assumptions, this model can be described in the form of a set of differential and algebraic equations, with state variables of the IM presented by appropriate spatial vectors in a stationary coordinate system $(\alpha-\beta)$, in relative quantities, [p.u.] [20]:

- Voltage equations of the stator and rotor windings:

$$
\begin{gathered}
T_{N} \frac{\mathrm{d}}{\mathrm{d} t} \mathbf{\Psi}_{s}=\mathbf{u}_{s}-r_{s} \mathbf{i}_{s} \\
T_{N} \frac{\mathrm{d}}{\mathrm{d} t} \Psi_{r}=\frac{r_{r}}{l_{r}}\left(l_{m} \mathbf{i}_{s}-\mathbf{\Psi}_{r}\right)+j \omega_{m} \mathbf{\Psi}_{r},
\end{gathered}
$$

- Flux-current equations:

$$
\begin{aligned}
& \boldsymbol{\Psi}_{s}=l_{s} \mathbf{i}_{s}+l_{m} \mathbf{i}_{r}, \\
& \mathbf{\Psi}_{r}=l_{r} \mathbf{i}_{r}+l_{m} \mathbf{i}_{s},
\end{aligned}
$$

- Equation of motion:

$$
T_{M} \frac{\mathrm{d}}{\mathrm{d} t} \omega_{m}=t_{e m}-t_{L}
$$

- $\quad$ Electromagnetic torque:

$$
t_{e m}=\operatorname{Im}\left(\mathbf{\Psi}_{s}^{*} \mathbf{i}_{s}\right),
$$

where: $\mathbf{u}_{s}, \mathbf{i}_{s}, \mathbf{\Psi}_{s}$-spatial vectors of the stator voltage, current, and flux, respectively; $\mathbf{i}_{r}, \mathbf{\Psi}_{r}$-spatial vectors of the rotor current and flux, respectively; $\omega_{m}$-rotor speed; $r_{s}$, $l_{s}$-stator resistance and inductance, respectively; $r_{r}, l_{r}$-rotor resistance and inductance, respectively; $l_{m}$-main inductance; $t_{L}$-load torque; $T_{M}$-mechanical time constant of the drive; $T_{N}=1 /\left(2 \pi f_{s N}\right)$-time constant resulting from [p.u.] system; $f_{s N}$-rated frequency of the stator winding.

The rotor and stator inductances are dependent on the main and leakage inductances as follows: $l_{r}=l_{\sigma r}+l_{m}, l_{s}=l_{\sigma s}+l_{m}$.

\subsection{Control Structure}

In this article, all studies have been carried out for the direct rotor flux-oriented control (DRFOC) structure [20] presented in Figure 1. To realize this vector-controlled method, current signals of the phase stator windings need to be converted to the stationary coordinate system $(\alpha-\beta)$, and next, to the coordinate system $(x-y)$ rotating at the rotor flux vector synchronous speed, $\omega_{s \psi}$. In this research, the stator current measurements only in $A$ 
and $B$ phases were assumed. This is the most popular solution in the industrial system. According to this, the stator current components are converted from the phase values to the stationary and next to the rotating components as follows:

$$
\begin{gathered}
i_{s \alpha}=i_{s A}, \\
i_{s \beta}=\frac{i_{s A}+2 i_{s B}}{\sqrt{3}}, \\
i_{s x}=i_{s \alpha} \cos \gamma_{\Psi}+i_{s \beta} \sin \gamma_{\Psi}, \\
i_{s y}=-i_{S \alpha} \sin \gamma_{\Psi}+i_{s \beta} \cos \gamma_{\Psi},
\end{gathered}
$$

where $\gamma_{\Psi}$ is the rotor flux vector angle (referred to phase $A$ of the stator winding) calculated on the basis of the rotor flux vector components:

$$
\gamma_{\Psi}=\tan ^{-1}\left(\frac{\Psi_{r \beta}}{\Psi_{r \alpha}}\right)
$$

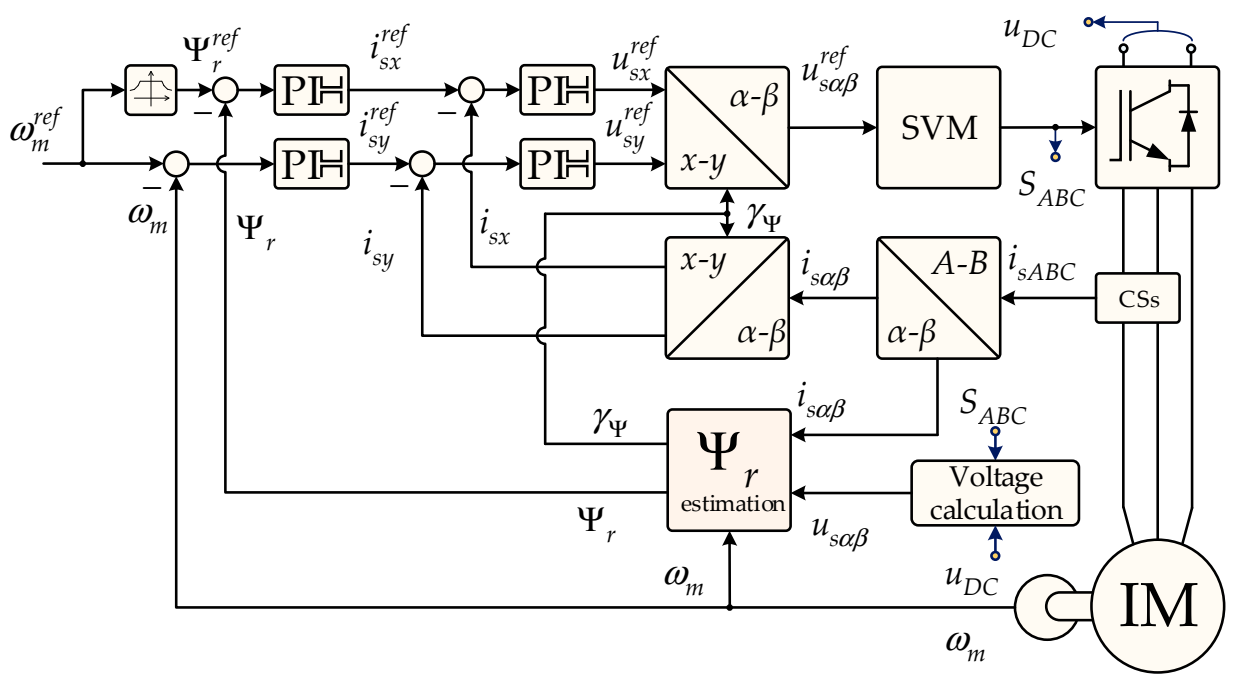

Figure 1. Basic scheme of the DRFOC structure.

Thanks to the transformation of the phase current values $A, B$ to the coordinate system rotating at a rotor flux velocity, it is possible to linearize the torque control of the IM through the independent stabilization of the rotor flux vector amplitude using the actual stator current vector component, $i_{s x}$, and to make the electromagnetic torque, $t_{e m}$, linearly dependent on the imaginary component of the stator current vector, $i_{s y}$ :

$$
t_{e m}=\frac{l_{m}}{l_{r}} \Psi_{r} i_{s y} .
$$

To realize this control method, it is necessary to estimate the rotor flux, $\mathbf{\Psi}_{r}$, and in the situation when some CS is faulty, the stator current vector, $\mathbf{i}_{s}$, also. In this article, all IM electromagnetic state variables were estimated using the Luenberger Observer (LO), under healthy and faulty conditions of the suitable CSs used in the drive system.

\subsection{Luenberger Observer for the IM}

A linear nonstationary full-order observer of the Luenberger type can be easily designed for the IM $[2,20]$. Thanks to this, it is possible to estimate the stator current and the rotor flux vectors, necessary in the described control structure, also in the CS post-fault 
operation, as is shown in the next sections. A mathematical model of the LO for the IM can be expressed as follows:

$$
T_{N} \frac{\mathrm{d}}{\mathrm{d} t} \hat{\mathbf{x}}=\mathbf{A}\left(\omega_{m}\right) \hat{\mathbf{x}}+\mathbf{B} \mathbf{u}_{s}+\mathbf{G}\left(\hat{\mathbf{i}}_{s}-\mathbf{i}_{s}\right)
$$

where:

- The vector of electromagnetic state variables:

$$
\hat{\mathbf{x}}=\left[\begin{array}{llll}
\hat{i}_{s \alpha} & \hat{i}_{s \beta} & \hat{\Psi}_{r \alpha} & \hat{\Psi}_{r \beta}
\end{array}\right]^{T}
$$

- The state matrix of the observer:

$$
\mathbf{A}\left(\omega_{m}\right)=\left[\begin{array}{cccc}
-\frac{r_{s}}{\sigma l_{s}}-\frac{(1-\sigma) r_{r}}{\sigma l_{r}} & 0 & \frac{l_{m} r_{r}}{\sigma l_{s} l_{r}^{2}} & \frac{l_{m}}{\sigma l_{s} l_{r}} \omega_{m} \\
0 & -\frac{r_{s}}{\sigma l_{s}}-\frac{(1-\sigma) r_{r}}{\sigma l_{r}} & -\frac{l_{m}}{\sigma l_{s} l_{r}} \omega_{m} & \frac{l_{m} r_{r}}{\sigma l_{s} l_{r}^{2}} \\
\frac{l_{m} r_{r}}{l_{r}} & 0 & -\frac{r_{r}}{l_{r}} & -\omega_{m} \\
0 & \frac{l_{m} r_{r}}{l_{r}} & \omega_{m} & -\frac{r_{r}}{l_{r}}
\end{array}\right]
$$

- $\quad$ The input matrix:

$$
\mathbf{B}=\left[\begin{array}{cccc}
\frac{1}{\sigma l_{s}} & 0 & 0 & 0 \\
0 & \frac{1}{\sigma l_{s}} & 0 & 0
\end{array}\right]^{T}
$$

- The control vector equal to stator voltage vector:

$$
\mathbf{u}_{s}=\left[\begin{array}{ll}
u_{s \alpha} & u_{s \beta}
\end{array}\right]^{T},
$$

- Luenberger observer gain matrix:

$$
\mathbf{G}=\left[\begin{array}{cccc}
g_{1} & g_{2} & g_{3} & g_{4} \\
-g_{2} & g_{1} & -g_{4} & g_{3}
\end{array}\right]^{T}
$$

and:

$$
\begin{gathered}
g_{1}=-\left(k_{0}-1\right)\left(\frac{r_{s}}{\sigma l_{s}}+\frac{r_{r}}{\sigma l_{r}}\right), \\
g_{2}=\left(k_{0}-1\right) \omega_{m}, \\
g_{3}=-\left(k_{0}^{2}-1\right)\left(\frac{l_{m} r_{r}}{l_{r}}-c\left(\frac{r_{s}}{\sigma l_{s}}+\frac{(1-\sigma) r_{r}}{\sigma l_{r}}\right)\right)+c\left(k_{0}-1\right)\left(\frac{r_{s}}{\sigma l_{s}}+\frac{r_{r}}{\sigma l_{r}}\right), \\
g_{4}=-c\left(k_{0}-1\right) \omega_{m},
\end{gathered}
$$

and: $\sigma=1-l_{m}^{2} /\left(l_{s} l_{r}\right), c=\sigma l_{s} l_{r} / l_{m}$, and $k_{0}$ is a positive coefficient.

The elements of the LO gain matrix were obtained based on the analysis of the observer stability using its characteristic equation $[2,20,21]$. It should be emphasized that the coefficient $k_{0}$ significantly influences the LO dynamic performance and its sensitivity to IM parameters mismatch (especially stator and rotor resistances) used in the observer model [21,22]. It is also analyzed in a further section from the point of view of the stator current estimation accuracy in the post-fault operation of the drive.

The components of the stator voltage $\mathbf{u}_{s}$ are not measured presently in the drive system but estimated based on the actual switching states $S_{A}, S_{B}$, and $S_{C}$ of the inverter IGBTs in $A, B$, and $C$ phases and on the measurement of the DC-bus voltage, $u_{D C}$. Thus, their values in the stationary coordinate frame $(\alpha-\beta)$ are as follows:

$$
u_{s \alpha}=\frac{2 S_{A}-S_{B}-S_{C}}{3} u_{D C}
$$




$$
u_{s \beta}=\frac{S_{B}-S_{C}}{\sqrt{3}} u_{D C} .
$$

The DRFOC structure with the $\mathrm{LO}$ is presented in Figure 2.

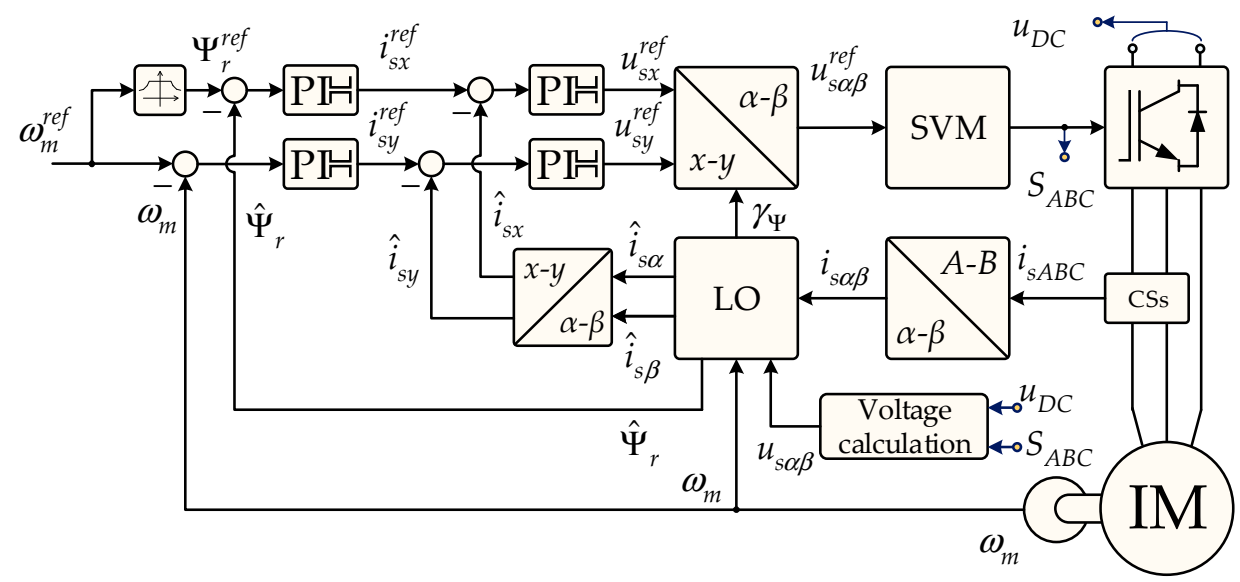

Figure 2. Scheme of the DRFOC structure with LO.

\subsection{Modified LO Used in CS Postfault Operation}

In the classical LO coefficient, $k_{0}$ is a positive constant and the difference between the estimated and measured currents in the $(\alpha-\beta)$ frame is used in the additional term with the G matrix (13). When some CS fault occurs, the estimated stator current can only be used in the LO mathematical model, as it was carried out in $[17,18]$. However, in these works, the value of the $k_{0}$ coefficient was taken close to one (i.e., in (19)-(22), the value of $\left(k_{0}-1\right)=$ 0.001 ), which, in fact, caused the LO to turn to the IM mathematical model itself (matrix $\mathbf{G} \approx 0$ ) and, thus, the stator current and rotor flux estimation was sensitive to the mismatch in motor parameters. To avoid such a situation, in this article, a different solution was proposed. Below, three LO operating scenarios, hereinafter referred to variants, $v_{1}-v_{3}$, are described.

In the first scenario, $v_{1}$, when both CSs are healthy, the classical current error defined as the difference between the estimated (by LO) and measured (meas) stator currents in the $(\alpha-\beta)$ frame is used in (13):

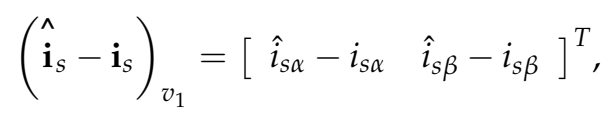

In a situation when one of the CSs is faulty, and thus its output value is equal to zero, there is no correct information about the current estimation error, and the state variable estimation is very ineffective for normally used $k_{0} \neq 1$ values in the gain matrix of LO. In such a situation, when the CS in phase $A$ loses the signal, Equation (25) takes the form:

$$
\left(\hat{\mathbf{i}}_{s}-\mathbf{i}_{s}\right)_{v_{1}^{A}}=\left[\begin{array}{ll}
\hat{i}_{s \alpha} & \hat{i}_{s \beta}-\frac{2 i_{s B}^{\text {meas }}}{\sqrt{3}}
\end{array}\right]^{T}
$$

and when the CS in phase $B$ loses the signal, the elements of the error vector in the LO model are as follows:

$$
\left(\hat{\mathbf{i}}_{s}-\mathbf{i}_{s}\right)_{v_{1}^{B}}=\left[\begin{array}{ll}
\hat{i}_{s \alpha}-i_{s \alpha} & \hat{i}_{s \beta}-\frac{i_{s A}^{\text {meas }}}{\sqrt{3}}
\end{array}\right]^{T},
$$

It is shown in the following section that such an approximation of the measured current in the stator phase with a faulty CS causes significant inaccuracy in the stator current reconstruction using the $\mathrm{LO}$ with $k_{0} \neq 1$. Therefore, in this research, other operation scenarios of the LO were proposed for the postfault operation mode. 
For the second variant, $v_{2}$, the corrected (corr) current values were applied based on the current measured by a healthy CS and estimated by the LO in the phase with a faulty CS:

$$
\begin{gathered}
i_{s \alpha}^{\text {corr }}=\left(1-\lambda_{A}\right) i_{s A}^{\text {meas }}+\lambda_{A} \hat{i}_{s A}, \\
i_{s \beta}^{\text {corr }}=\frac{\left(1-\lambda_{A}\right) i_{s A}^{\text {meas }}+\left(1-\lambda_{B}\right) 2 i_{s B}^{\text {meas }}+\lambda_{A} \hat{i}_{s A}+\lambda_{B} 2 \hat{i}_{s B}}{\sqrt{3}},
\end{gathered}
$$

where $\lambda_{A / B}$ is equal to 0 for a healthy CS and is equal to 1 for a faulty CS in a given phase.

The solution presented in [23] was used for the CS's fault detection and localization. This algorithm is based on a comparison of the squared difference between the measured and estimated currents in a given phase with some threshold value. If this value is bigger than the adopted threshold, $\vartheta$, the $\lambda_{A / B}$ coefficient changes its value from 0 to 1 .

In order to avoid a change in $\lambda_{A / B}$ value when the current difference becomes lower than the accepted threshold at time moments close to zero crossing of the phase current, the $\lambda_{A / B}$ values are stored after the sensor failures are detected:

$$
\lambda_{A / B}(k)=\left\{\begin{array}{lll}
1 & \text { for } \quad \varepsilon_{A / B}(k)=\left(i_{s A / B}^{\text {meas }}(k)-\hat{i}_{S A / B}(k)\right)^{2} \geq \vartheta \\
0 & \text { for } \quad \varepsilon_{A / B}(k)=\left(i_{s A / B}^{\text {meas }}(k)-\hat{i}_{S A / B}(k)\right)^{2}<\vartheta \quad \text { and } \quad \lambda_{A / B}(k-1) \neq 1
\end{array} .\right.
$$

The phase stator currents are calculated by the reverse Clarke transformation:

$$
\begin{gathered}
\hat{i}_{s A}=\hat{i}_{s \alpha,} \\
\hat{i}_{s B}=-\frac{1}{2}\left(\hat{i}_{s \alpha}-\sqrt{3} \hat{i}_{s \beta}\right),
\end{gathered}
$$

Finally, the stator current estimation error can be presented as follows:

$$
\left(\hat{\mathbf{i}}_{s}-\mathbf{i}_{s}\right)_{v_{2}}=\left[\begin{array}{ll}
\hat{i}_{s \alpha}-i_{s \alpha}^{c o r r} & \hat{i}_{s \beta}-i_{s \beta}^{c o r r}
\end{array}\right]^{T}
$$

The third variant, $v_{3}$, is based only on the estimation error between the measured current in the stator winding phase with a healthy CS and the current in this phase estimated by the LO. In this solution, the same error in each axis is used, assuming their similar values under healthy CS conditions due to the high estimation quality of the observer with properly designed gains. When the CS in phase $A$ is faulty, only currents (measured and estimated) in phase $B$ are used, and vice versa:

$$
\begin{aligned}
& \left(\hat{\mathbf{i}}_{s}-\mathbf{i}_{s}\right)_{v_{3}^{A}}=\left[\begin{array}{ll}
\hat{i}_{s B}-i_{s B}^{\text {meas }} & \hat{i}_{s B}-i_{s B}^{\text {meas }}
\end{array}\right]^{T}, \\
& \left(\hat{\mathbf{i}}_{s}-\mathbf{i}_{s}\right)_{v_{3}^{B}}=\left[\begin{array}{ll}
\hat{i}_{s A}-i_{s A}^{m e a s} & \hat{i}_{s A}-i_{s A}^{\text {meas }}
\end{array}\right]^{T} .
\end{aligned}
$$

In the next section, the impact of the design factor $k_{0}$ in the observer gain matrix $\mathbf{G}$ on the above operation variants $v_{1}-v_{3}$ of the $\mathrm{LO}$ in the DRFOC drive system is analyzed.

\section{Quality of the Stator Current Estimation in CS Postfault Operation}

\subsection{Simulation Assumptions}

All simulation tests were realized in the MATLAB/Simulink environment. To solve the differential equations describing the IM, the Euler integration method (ode1) was used, with sampling time $T_{s}=6.25 \times 10^{-6}$. Rated parameters of the IM are presented in the Appendix A (Table A1). In order to bring the simulation conditions closer to the real ones, random noises were introduced for electrical and mechanical signals used in the control structure. 
For the stator current and DC bus voltage measurements, these noises are defined as follows:

$$
x^{\text {meas }}=x^{i d}+1.01 \times 10^{-4}\left(\frac{1}{a-1.01}+\frac{1}{1.01}\right) b,
$$

where $x^{i d}$ is an ideal value of a signal, $a$ is a random value from 0 to 1 , and $b$ is a random value of -1 and 1 .

The error in counting encoder pulses is given as:

$$
\omega^{\text {meas }}=\omega^{i d}+\frac{c}{n_{N}}
$$

where $\omega^{\text {id }}$ is an ideal value of a rotor angular speed, and $c$ is a random integer value ranging from -3 to 3 , with a probability of $0.05 \%$ for $-3,-2,2$, and $3 ; 0.1 \%$ for -1 and 1 ; and $99.6 \%$ for 0 .

The results can be seen in Figure 3.

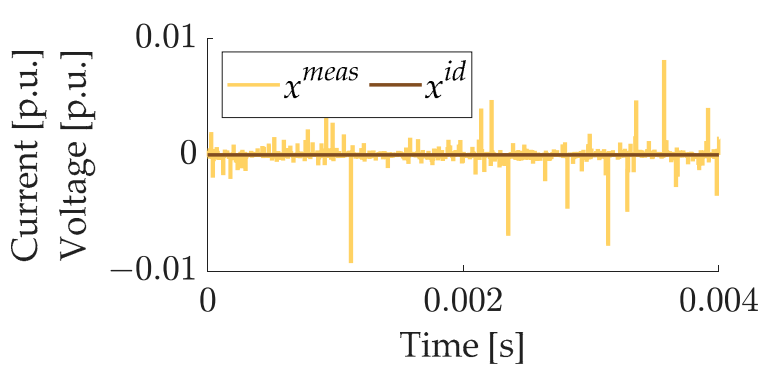

(a)

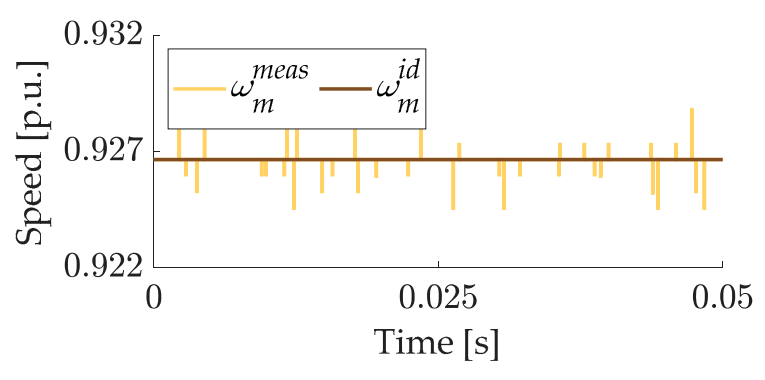

(b)

Figure 3. Noises in current and voltage measurements (a) and error in counting encoder pulses (b).

\subsection{Impact of the LO Design Parameters on Stator Current Estimation Quality}

In this section, the quality of the stator current estimation for different $k_{0}$ values in the LO gain matrix and three analyzed variants of the stator current error in the LO model depending on the CS fault occurrence are tested. In simulation research, the most popular is assuming the same values of the parameters in mathematical models of the IM and estimators. As shown in [16], in such a case, the estimated and measured currents are almost identical. Therefore, in the research presented in this article, some random inaccuracy of the IM parameters used in the LO mathematical model was taken into account.

For a random value in the range from 0 to 1 , it was determined whether the parameter error will be accepted in excess or under its rated value. Identification errors are mostly in the range of $\pm 10 \%$; therefore, such a range, with an accuracy to one decimal place, has been adopted in further studies. The leakage inductances of the stator and rotor windings of the IM are assumed to be equal, $L_{\sigma r}=L_{\sigma s}$. Based on the above, the values of the parameters used in the LO are presented in Table 1.

Table 1. Assumed inaccuracy of the IM parameters used in LO model.

\begin{tabular}{cccccc}
\hline $\mathbf{0}$ & $\boldsymbol{r}_{\boldsymbol{r}}$ & $\boldsymbol{r}_{\boldsymbol{s}}$ & $\boldsymbol{l}_{\boldsymbol{m}}$ & $\boldsymbol{l}_{\boldsymbol{\sigma r}}$ & $\boldsymbol{l}_{\boldsymbol{\sigma s}}$ \\
\hline$\%$ of rated value & 106.2 & 96.1 & 108.9 & 98.4 & 98.4 \\
\hline
\end{tabular}

The quality of the stator current estimation was evaluated using the average value of the absolute difference between the IM stator current signal (without measuring noise) and the current estimated by the LO, in the stationary frame $(\alpha-\beta)$ : 


$$
\varepsilon_{i k}=\frac{t_{2}-t_{1}}{T_{s}} \sum_{p=t_{1} / T_{s}}^{t_{2} / T_{s}}\left|\hat{i}_{s k}(p)-\hat{i}_{s k}^{I M}(p)\right|, k \in\{\alpha, \beta\} .
$$

where index $k$ refers to both stator current vector components, $T_{s}$ is sampling time, and $t_{1}$, $t_{2}$ are the signal analysis intervals.

The final quality index for the current estimation is an average of $(\alpha-\beta)$ indices:

$$
\varepsilon_{i}=\frac{\varepsilon_{i \alpha}+\varepsilon_{i \beta}}{2} .
$$

All tests were realized for two different values of rotor speeds (50\% and $100 \%$ of the rated speed) and load torques ( $25 \%$ and $75 \%$ of the rated torque). First, the case of CS fault in the $A$ phase was tested, for four combinations of above speed and load torque values. All results are shown in Figures 4 and 5.

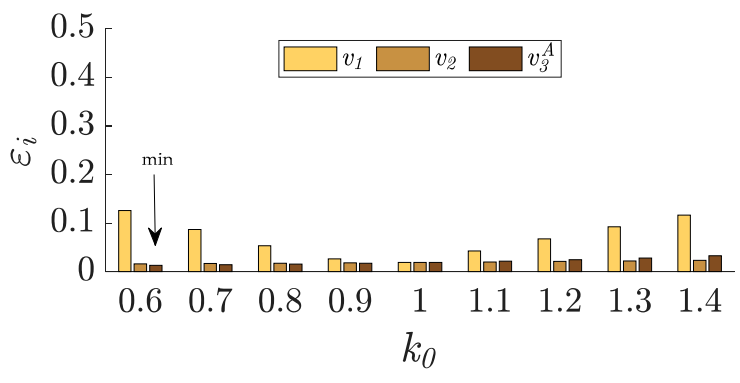

(a)

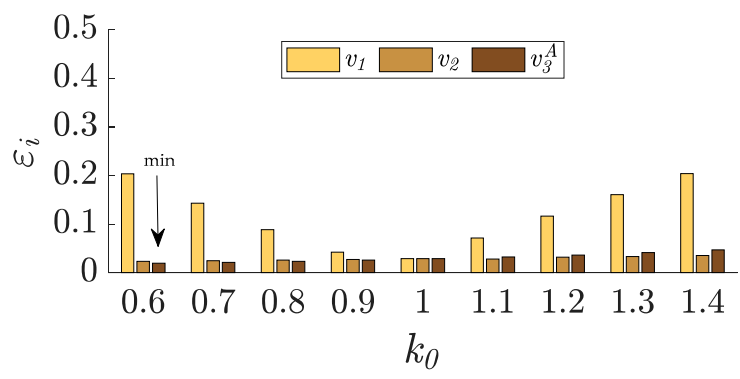

(b)

Figure 4. Error index of stator current estimation for $\omega_{m}=0.5 \omega_{m N}$ and faulty CS in phase $A$ : (a) $t_{L}=0.25 t_{L N} ;(\mathbf{b}) t_{L}=0.75 t_{L N}$.

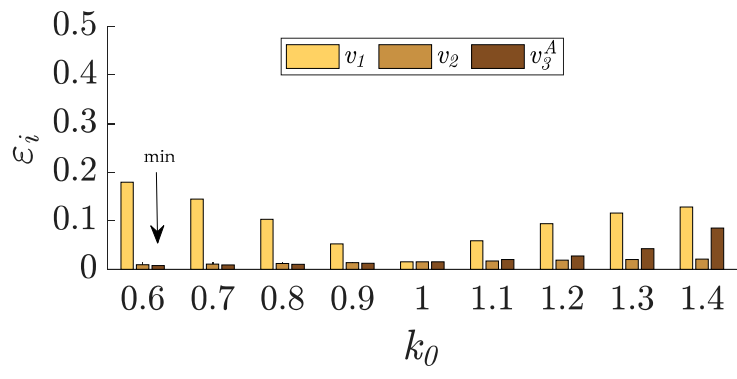

(a)

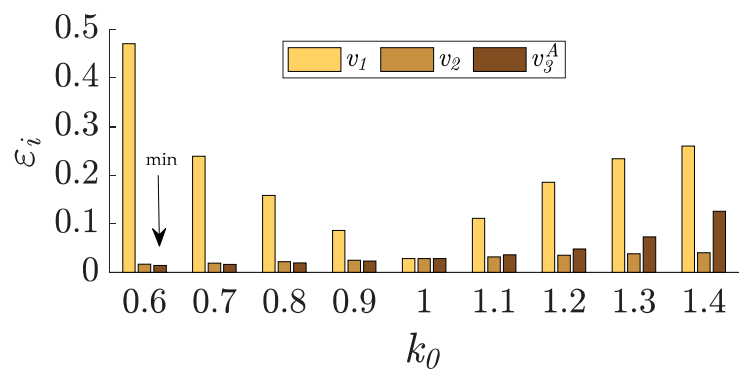

(b)

Figure 5. Error index of stator current estimation for $\omega_{m}=\omega_{m N}$ and faulty CS in phase $A$ : (a) $t_{L}=0.25 t_{L N} ;(\mathbf{b}) t_{L}=0.75 t_{L N}$.

As can be seen above, for different speeds and load torques, the best results are obtained for variant $v_{3}$ and $k_{0}=0.6$. It is the most visible for the rated speed and $75 \%$ of the rated load torque. Next, a similar test but for the CS fault in the $B$ phase was realized. The results of the current estimation quality are shown in Figures 6 and 7. 


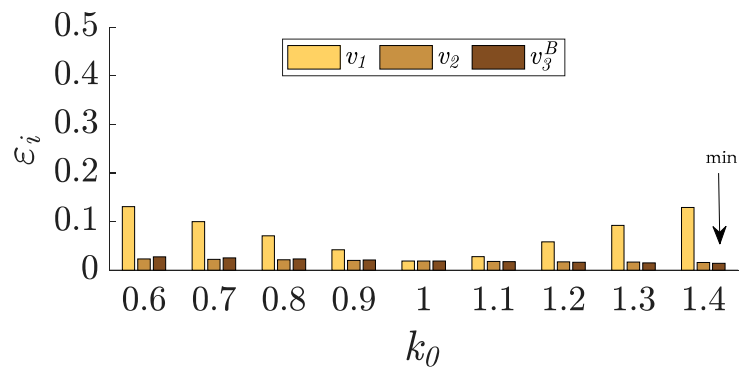

(a)

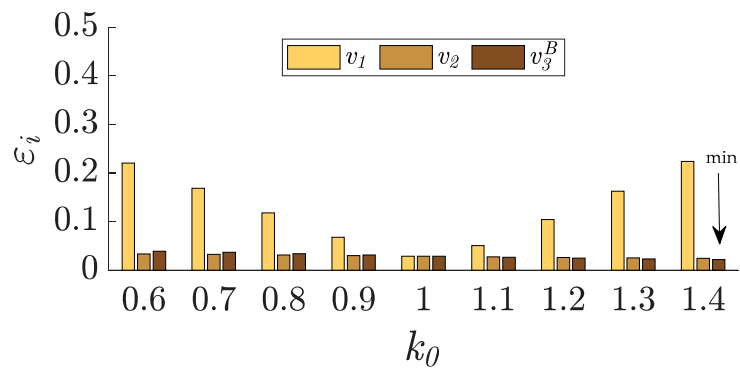

(b)

Figure 6. Error index of stator current estimation for $\omega_{m}=0.5 \omega_{m N}$ and faulty CS in phase $B:(\mathbf{a}) t_{L}=0.25 t_{L N} ;(\mathbf{b}) t_{L}=0.75 t_{L N}$.

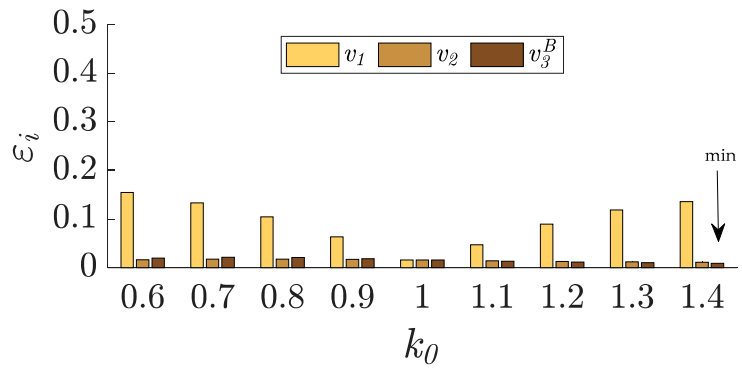

(a)

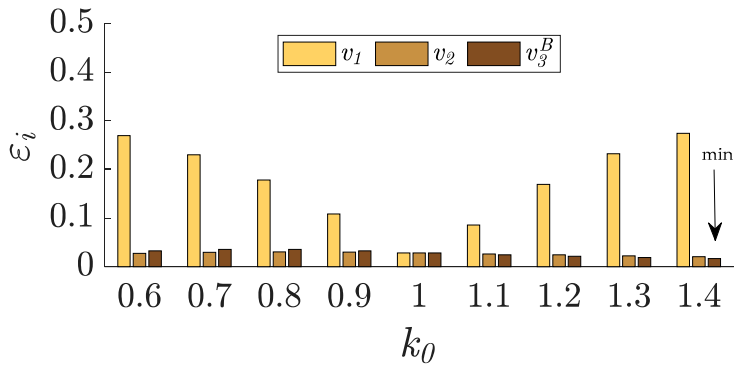

(b)

Figure 7. Error index of stator current estimation for $\omega_{m}=\omega_{m N}$ and faulty CS in phase $B$ : (a) $t_{L}=0.25 t_{L N} ;(\mathbf{b}) t_{L}=0.75 t_{L N}$.

When the CS in phase $B$ is faulty, the best quality of the stator current estimation is obtained for $k_{0}=1.4$ and also for variant $v_{3}$. Figures $4-7$ show that the CS fault in $A$ phase has a bigger impact on the quality of stator current reconstruction, especially for the classical LO (variant $v_{1}$ ). This is due to the equivalence of the $A$ phase and $\alpha$ axis. Introducing the proposed modifications (variants $v_{2}$ and $v_{3}$ ) significantly reduces the error of the stator current estimation in postfault operation of the LO-based drive system.

Therefore, the waveforms of the estimated and measured currents in phase $A$, for $k_{0}=0.6$ and three analyzed variants of the LO model, are shown in Figure 8, with the quality indices calculated using Equation (39). It should be noted that, especially for the variant $v_{1}$, the stator current approximation given by Equation (26) causes significant inaccuracy in the stator current reconstruction using the LO with $k_{0} \neq 1$.

Additionally, the case with a specific value of $k_{0}=1$ is also presented in Figure 9. For this value of coefficient $k_{0}$, the feedback from the stator current error is not used in the LO, so the choice of the LO variant does not affect the quality of the current estimation (see Figures 4-7). For $k_{0}=1$, the LO gives identical results such as VCS [16] mentioned earlier. However, its sensitivity to the motor parameter mismatch is larger compared to a properly designed LO with $k_{0} \neq 1$, as it is shown in the presented test results.

Basing on the obtained results, the self-correcting CS was developed, which, according to the detected sensor fault in a given motor phase, enables the proper reconstruction of the stator current in missing phase using the modified LO. 


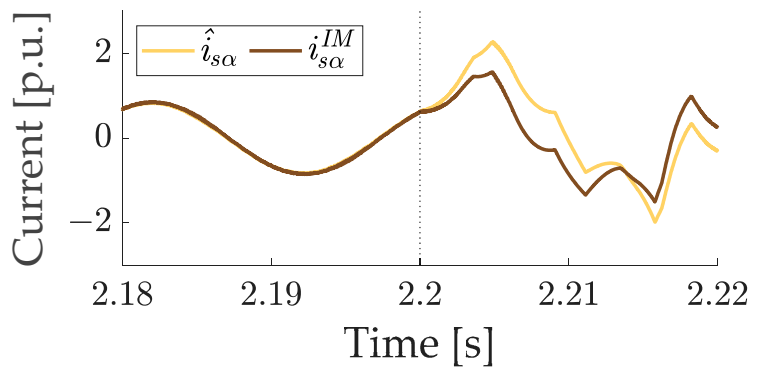

(a)

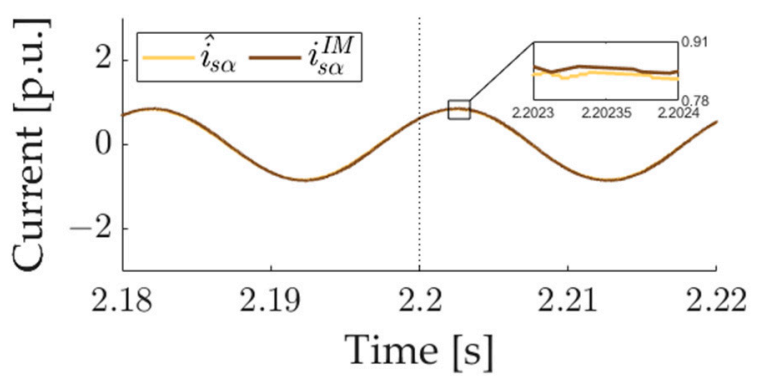

(c)

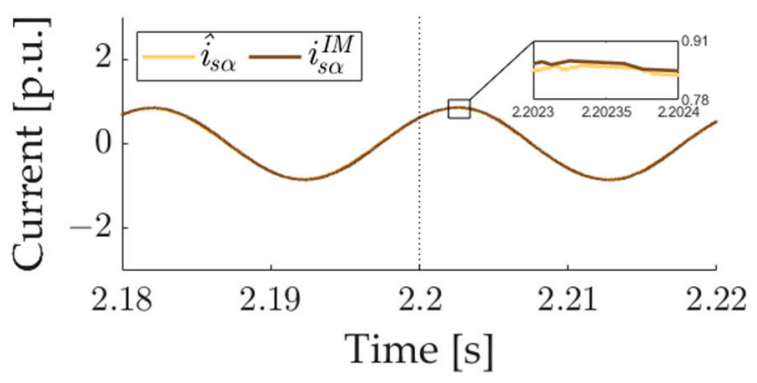

(e)

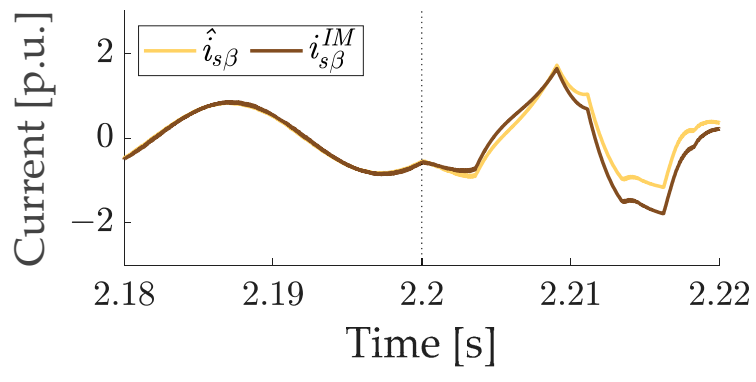

(b)

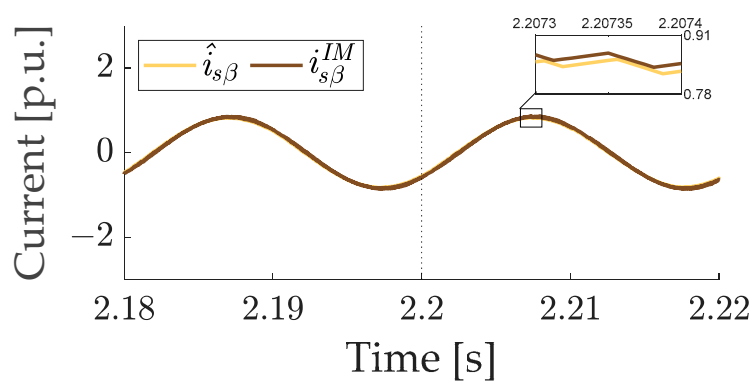

(d)

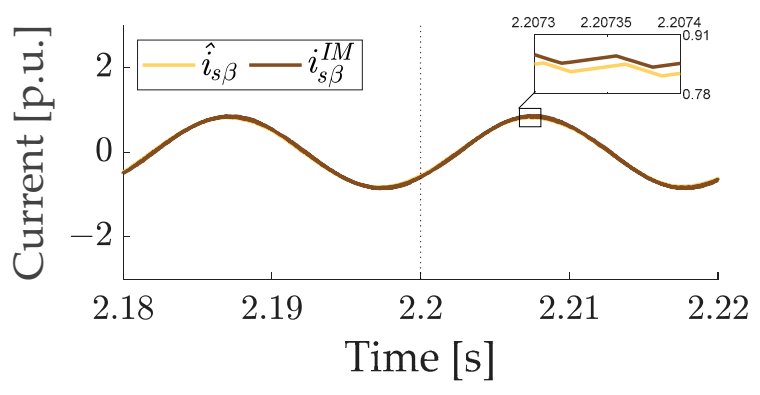

(f)

Figure 8. Estimated and IM components $\alpha(\mathbf{a}, \mathbf{c}, \mathbf{e})$ and $\beta(\mathbf{b}, \mathbf{d}, \mathbf{f})$ of the stator current vector for $k_{0}=0.6$ and faulty CS in phase $A$ : $(\mathbf{a}, \mathbf{b})$ variant $v_{1}, \varepsilon_{i}=0.4702 ;(\mathbf{c}, \mathbf{d})$, variant $v_{2}, \varepsilon_{i}=0.0167 ;(\mathbf{e}, \mathbf{f})$, variant $v_{3}, \varepsilon_{i}=0.01425$.

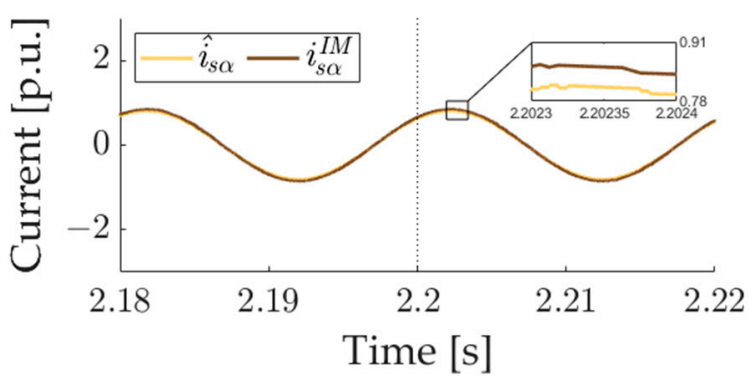

(a)

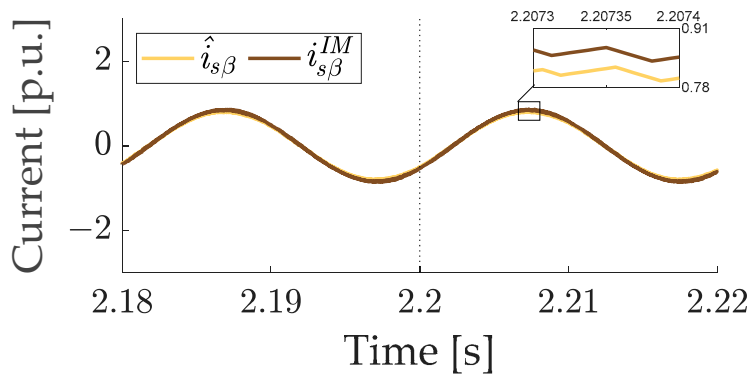

(b)

Figure 9. Estimated and IM components $\alpha(\mathbf{a})$ and $\beta(\mathbf{b})$ of the stator current for $k_{0}=1$ and faulty CS in phase $A, \varepsilon_{i}=0.02845$.

\section{Influence of the IM Resistance Changes on Self-Correcting CS}

In IM, the stator and rotor resistances are the most changeable parameters because they are dependent on the winding temperature, which changes during the drive system operation. Therefore, the analysis of stator current reconstruction quality with the proposed self-correcting CS was performed for $r_{r}^{I M}=$ var or / and $r_{S}{ }^{I M}=$ var (to $130 \%$ of their rated values). Their inertial changes were adopted, as shown in Figure 10. Changes in 
resistance values in the IM are slow; however, for simulation studies, the time interval of resistance changes was significantly reduced in relation to the real process, to shorten the simulation time.

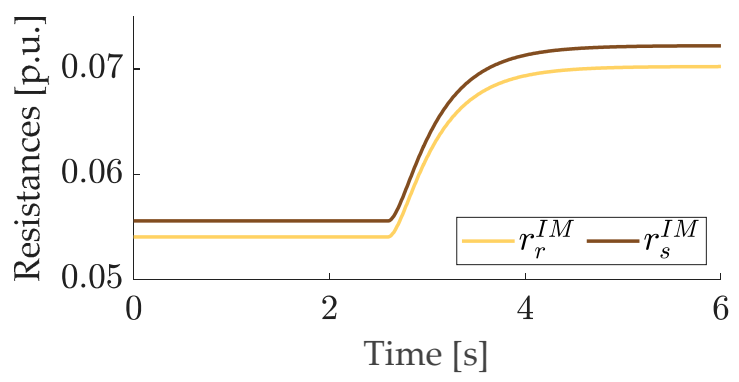

Figure 10. Assumed changes of rotor and stator resistances in IM model.

In this research, simultaneous changes in the IM winding resistances were modeled under a CS fault in the $A$ or $B$ phase. Two cases were compared:

1. When coefficient $k_{0}=1$ is used in the LO gain matrix;

2. When the optimal values of this coefficient are assumed, obtained in previous tests: for LO operating scenario $v_{3}$ and $k_{0}=0.6$ for CS fault in $A$ phase or $k_{0}=1.4$ for CS fault in $B$ phase, respectively.

In this study, the following working conditions of the drive system were assumed: After stabilization of the rotor flux, a rated speed was set on the ramp for the reference value. Then, $75 \%$ of the rated load was applied in $t=1.5 \mathrm{~s}$, also with the ramp. The total loss of signal in a given CS occurred in $t=2.2 \mathrm{~s}$. Resistance changes were in accordance with plots in Figure 10. In $t=4.5 \mathrm{~s}$, the speed was lowered to half of the rated speed. The reference trajectories of the rotor flux amplitude, motor speed, and the load torque are shown in Figure 11.

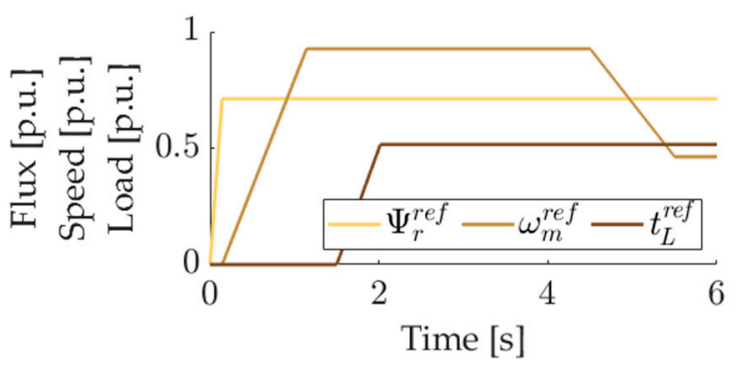

Figure 11. Reference trajectories of the rotor flux amplitude, motor speed, and load torque.

The influence of the changeable stator and rotor resistance of the IM windings depending on the faulty CS and adopted parameters of the modified LO is demonstrated in the following figures. In Figure 12, the CS fault in phase $A$ was tested, while in Figure 13, the same was performed for phase $B$. In these plots, in the time period between $t=2.20 \mathrm{~s}$ and $t=2.21 \mathrm{~s}$, the suitable components of the stator current are shown for the healthy drive, with rated parameters set in the IM and observer model. Next, the CS fault in phase $A$ or $B$ is simulated and the stator current estimation using the $\mathrm{LO}$ with gain matrix $\mathbf{G}=0$ for $k_{0}=1$ is shown in Figures 12a,c and 13a,c. On the contrary, in Figures 12b,d and 13b,d, the current reconstruction is shown for the modified LO operating based on the current errors described by (34) and (35) for operating mode $v_{3}$. 


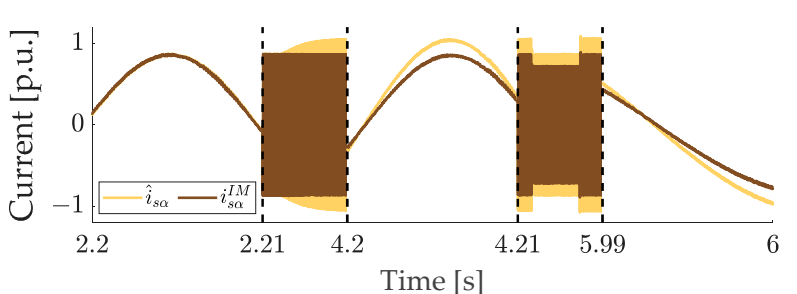

(a)

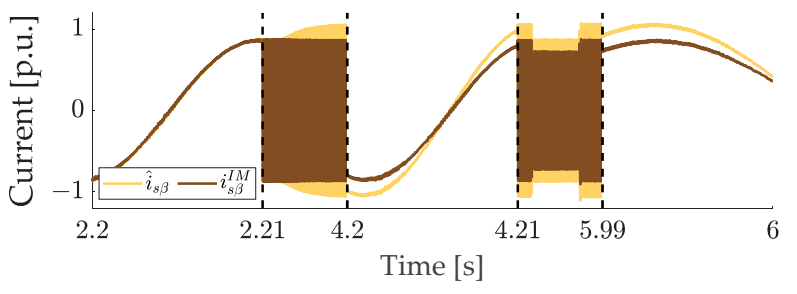

(c)

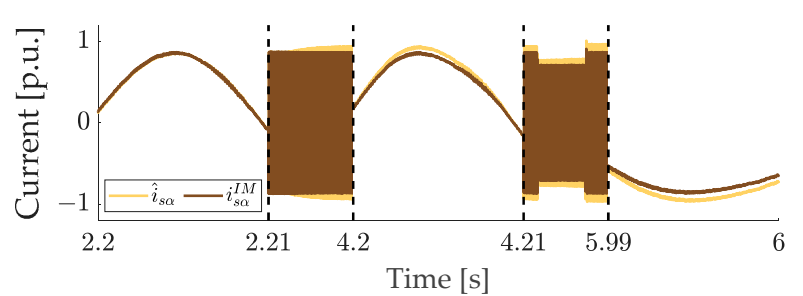

(b)

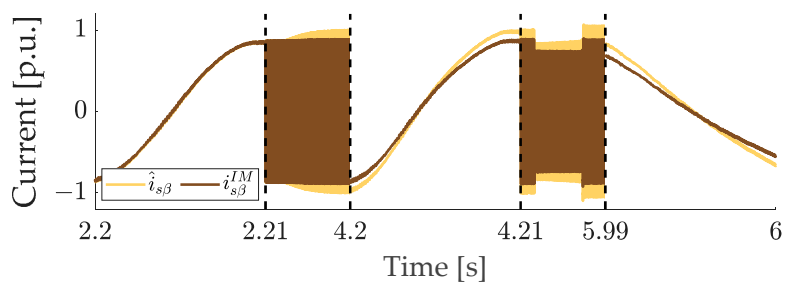

(d)

Figure 12. Estimated and measured stator current in $\alpha$ axis $(\mathbf{a}, \mathbf{b})$ and $\beta$ axis (c,d) during CS fault in phase $A$ for: $k_{0}=1$ $(\mathbf{G}=0)(\mathbf{a}, \mathbf{c})$ and $v_{3}$ operation mode for $k_{0}=0.6(\mathbf{b}, \mathbf{d}) ; r_{r}^{I M}=$ var, $r_{s}{ }^{I M}=$ var.

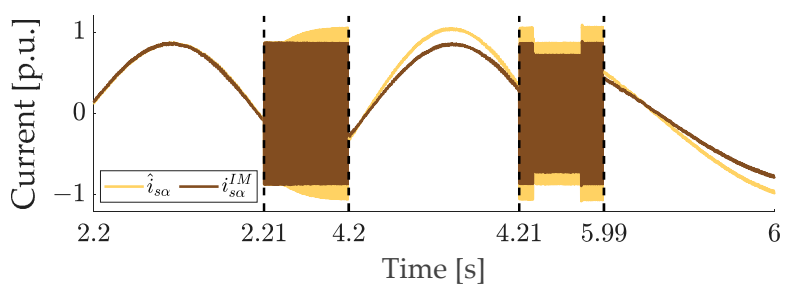

(a)

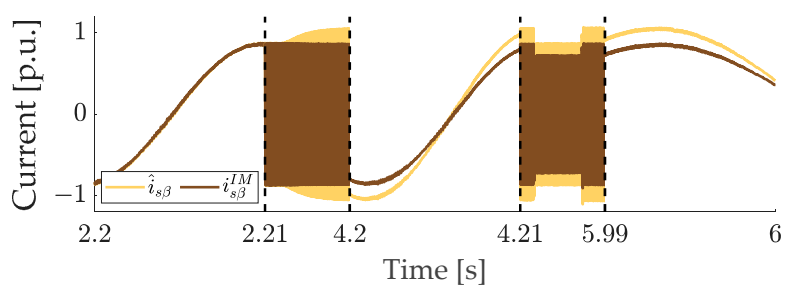

(c)

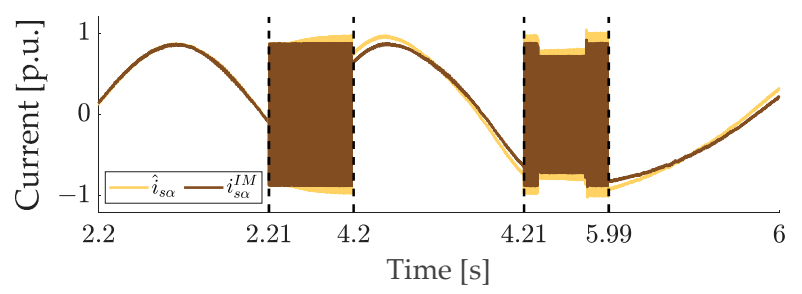

(b)

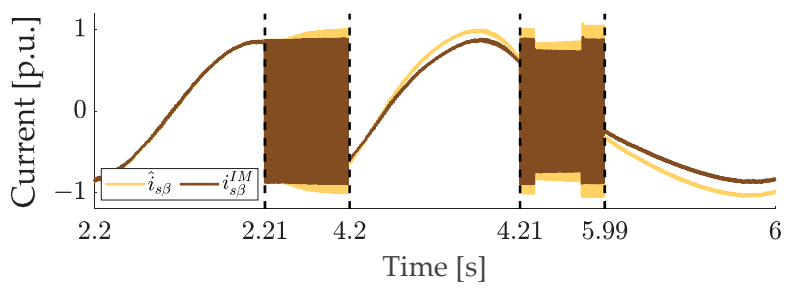

(d)

Figure 13. Estimated and measured stator current in $\alpha$ axis $(\mathbf{a}, \mathbf{b})$ and $\beta$ axis $(\mathbf{c}, \mathbf{d})$ during CS fault in phase $B$ for: $k_{0}=1$ $(\mathbf{G}=0)(\mathbf{a}, \mathbf{c})$ and $v_{3}$ operation mode for $k_{0}=1.4(\mathbf{b}, \mathbf{d}) ; r_{r}^{I M}=$ var, $r_{s}{ }^{I M}=$ var.

\section{Analysis of IM Drive System Operation with Self-Correcting CS}

The last point of the research presented in this article is the analysis of the IM drive behavior during post-fault operation with the proposed self-correcting CS. The working conditions of the drive are the same as described in Section 4. The influence of the CS fault in phase $A$ was analyzed, because, as shown in Section 3 , it has a more negative impact on the control structure.

In Figure 14, the rotor flux and angular velocity are presented with suitable zooms in the time interval when the rotor flux and speed reach their reference values, as well as in the moment of CS fault occurrence and the initial period of the introduced stator and rotor resistance changes. It should be emphasized that the ripples visible in the actual speed transient are caused by measurement noise, which are introduced in all simulation tests. However, they do not influence the system operation, including the LO-based self-correcting virtual CS. 


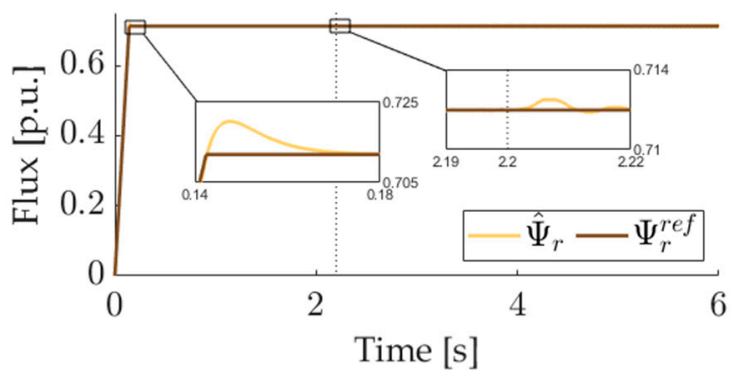

(a)

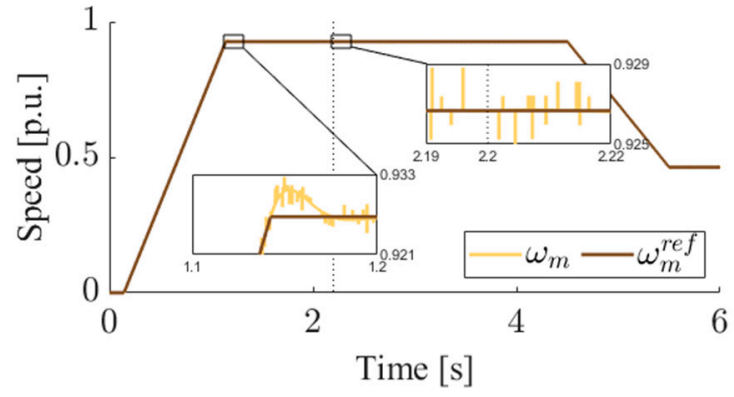

(b)

Figure 14. Waveforms of the rotor flux amplitude (a) and angular speed (b).

The measured and estimated currents in phases $A$ and $B$ are shown in Figure 15. As can be seen in Figure 15a, in $2.2 \mathrm{~s}$, the CS signal in phase $A$ is lost. After occurrence of the CS fault in phase $A$, the squared difference between measured and estimated currents, according to (30), significantly increases and exceeds the threshold $\vartheta$ (Figure 16a). As a result, the system leads to simultaneous fault detection and localization (Figure 16b) and determination of the $k_{0}$ coefficient in the $\mathrm{LO}$ gain matrix (Figure 16c) to enable the correct reconstruction of the stator current (Figure 15b).

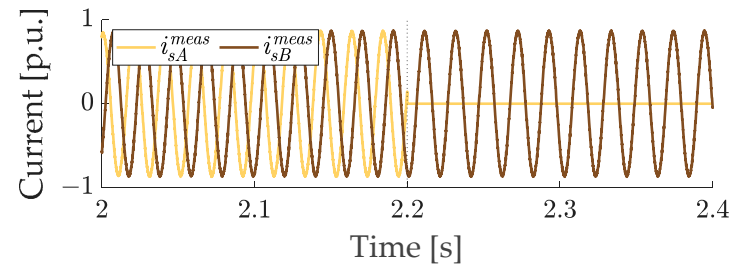

(a)

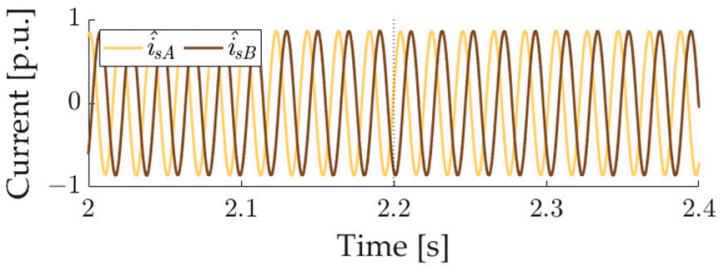

(b)

Figure 15. Measured (a) and estimated (b) stator currents in phases $A$ and $B$.

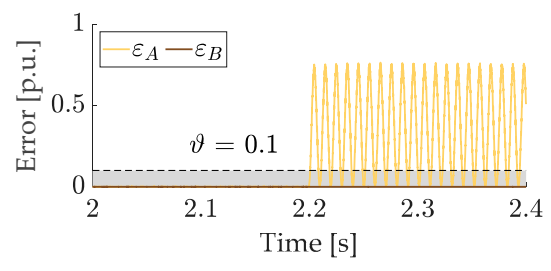

(a)

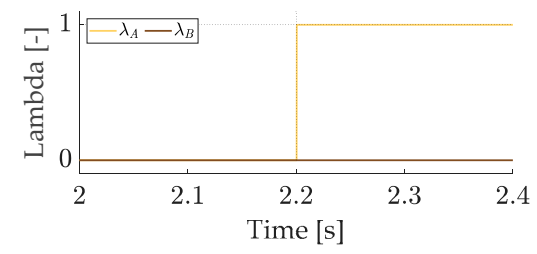

(b)

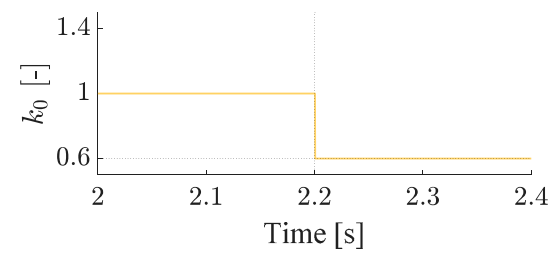

(c)

Figure 16. CS fault detection (a), localization (b), and change in $k_{0}$ coefficient in G matrix (c).

As can be seen from the presented figures, the control structure works properly. The rotor flux is stabilized throughout the studied operating range, and the angular velocity correctly follows the reference value. In addition, the virtual CS based on the proposed modified LO properly reconstructs the stator current after the failure of the measuring sensor in a given motor phase.

\section{Conclusions}

Extensive analysis of the quality of stator current estimation for various operating points of the DRFOC drive with the IM after CS faults in motor phase $A$ or $B$ has shown that the use of the proposed self-correcting virtual CS, based on the modified LO, significantly improves the estimation quality in relation to the classic approach. Changing the $\mathrm{G}$ matrix input allows us to provide information about the current estimation error vector in the LO mathematical model, regardless of the phase in which the CS failure occurred. 
The system detects and locates the CS fault very quickly and takes appropriate action to maintain the full functionality of the DRFOC drive. Thus, the fault-tolerant control system is obtained. Additionally, the system is able to work even if all CSs fail. This situation is considered when $k_{0}=1$ is used in the LO algorithm, because the measured currents are then not used in any way in the control structure. In such a situation, the LO is equal to the VCS proposed and tested in [16].

Author Contributions: Both authors contributed equally to the concept of the paper, and proposed the methodology, formal analyses, and validation, M.A. and T.O.-K.; software, M.A.; investigation, M.A. and T.O.-K.; data curation, M.A.; writing—original draft preparation, M.A.; writing-review and editing, T.O.-K.; visualization, M.A.; supervision, project administration, and funding acquisition, T.O.-K. All authors have read and agreed to the published version of the manuscript.

Funding: This research was supported by statutory funds of the Department of Electrical Machines, Drives and Measurements of the Faculty of Electrical Engineering, Wroclaw University of Science and Technology under grant 8211104160 (2021).

Institutional Review Board Statement: Not applicable.

Informed Consent Statement: Not applicable.

Data Availability Statement: Not applicable.

Conflicts of Interest: The authors declare no conflict of interest.

\section{Appendix A}

Table A1. Rated parameters of the tested induction motor.

\begin{tabular}{ccc}
\hline Symbol & [ph.u.] & [p.u.] \\
\hline Rated phase voltage, $U_{f N}$ & $230 \mathrm{~V}$ & 0.707 \\
Rated phase current, $I_{f N}$ & $2.5 \mathrm{~A}$ & 0.707 \\
Rated power, $P_{N}$ & $1.1 \mathrm{~kW}$ & 0.638 \\
Rated speed, $n_{N}$ & $1390 \mathrm{rpm}$ & 0.927 \\
Rated torque, $T_{e N}$ & $7.56 \mathrm{Nm}$ & 0.688 \\
Number of pole pairs, $p_{b}$ & 2 & - \\
Rotor winding resistance, $R_{r}$ & $4.968 \Omega$ & 0.0540 \\
Stator winding resistance, $R_{S}$ & $5.114 \Omega$ & 0.0556 \\
Rotor leakage inductance, $L_{\sigma r}$ & $31.6 \mathrm{mH}$ & 0.1079 \\
Stator leakage inductance, $L_{\sigma s}$ & $31.6 \mathrm{mH}$ & 0.1079 \\
Main inductance, $L_{m}$ & $541.7 \mathrm{mH}$ & 1.8498 \\
Rated rotor flux, $\Psi_{r N}$ & $0.7441 \mathrm{~Wb}$ & 0.7187 \\
Rated stator flux, $\Psi_{s N}$ & $0.8235 \mathrm{~Wb}$ & 0.7954 \\
Mechanical time constant, $T_{M}$ & $0.25 \mathrm{~s}$ & - \\
\hline
\end{tabular}

\section{References}

1. Mustafa, M.O.; Nikolakopoulos, G.; Gustafsson, T. Faults Classification Scheme for Three Phase Induction Motor. Int. J. Syst. Dyn. Appl. 2014, 3, 1-20. [CrossRef]

2. Vas, P. Sensorless Vector and Direct Torque Control; Oxford University Press: New York, NY, USA, 1998.

3. Kazmierkowski, M.P.; Krishnan, R.; Blaabjerg, F. Control in Power Electronics—Selected Problems; Academic Press: Cambridge, MA, USA, 2002.

4. Gaeta, A.; Scarcella, G.; Scelba, G.; De Caro, S.; Testa, A. Inverter fault-identification for VSI motor drives. In Proceedings of the 8th IEEE Symposium on Diagnostics for Electrical Machines, Power Electronics \& Drives, SDEMPED 2011, Bologna, Italy, 5-8 September 2011.

5. Orlowska-Kowalska, T.; Sobanski, P. Simple diagnostic technique of a single IGBT open-circuit faults for a SVM-VSI vector controlled induction motor drive. Bull. Pol. Acad. Sci. Tech. Sci. 2015, 63, 281-288. [CrossRef]

6. Najafabadi, T.A.; Salmasi, F.R.; Jabehdar-Maralani, P. Detection and isolation of speed-, DC-link voltage-, and current-sensor faults based on an adaptive observer in induction-motor drives. IEEE Trans. Ind. Electron. 2010, 58, 1662-1672. [CrossRef]

7. Dybkowski, M.; Klimkowski, K.; Orlowska-Kowalska, T. Speed and Current Sensor Fault-Tolerant-Control of the Induction Motor Drive. In Advanced Control of Electrical Drives and Power Electronic Converters; Kabzinski, J., Ed.; Springer: Berlin/Heidelberg, Germany, 2017; Volume 75, pp. 141-167. 
8. Manohar, M.; Das, S. Current sensor fault-tolerant control for direct torque control of induction motor drive using flux-linkage observer. IEEE Trans. Ind. Inform. 2017, 13, 2824-2833. [CrossRef]

9. Lee, K.S.; Ryu, J.S. Instrument fault detection and compensation scheme for direct torque controlled induction motor drives. IEE Proc.-Control Theory Appl. 2003, 150, 376-382. [CrossRef]

10. Green, T.C.; Williams, B.W. Derivation of motor line-current waveforms from the DC-link current of an inverter. IEE Proc. B Electr. Power Appl. 1989, 136, 196-204. [CrossRef]

11. Lee, W.C.; Hyun, D.S.; Lee, T.K. A novel control method for three-phase PWM rectifiers using a single current sensor. IEEE Trans. Power Electron. 2000, 15, 861-870.

12. Wang, W.; Cheng, M.; Wang, Z.; Zhang, B. Fast switching direct torque control using a single DC-link current sensor. J. Power Electron. 2012, 12, 895-903. [CrossRef]

13. Xu, Y.; Yan, H.; Zou, J.; Wang, B.; Li, Y. Zero voltage vector sampling method for PMSM three-phase current reconstruction using single current sensor. IEEE Trans. Power Electron. 2017, 32, 3797-3807. [CrossRef]

14. Salmasi, F.R. A self-healing induction motor drive with model free sensor tampering and sensor fault detection, isolation, and compensation. IEEE Trans. Ind. Electron. 2017, 64, 6105-6115. [CrossRef]

15. Chakraborty, C.; Verma, V. Speed and current sensor fault detection and isolation technique for induction motor drive using axes transformation. IEEE Trans. Ind. Electron. 2014, 62, 1943-1954. [CrossRef]

16. Adamczyk, M.; Orlowska-Kowalska, T. Virtual Current Sensor in the Fault-Tolerant Field-Oriented Control Structure of an Induction Motor Drive. Sensors 2019, 19, 4979. [CrossRef] [PubMed]

17. Azzoug, Y.; Sahraoui, M.; Pusca, R.; Ameid, T.; Romary, R.; Cardoso, A.J.M. High-performance vector control without AC phase current sensors for induction motor drives: Simulation and real-time implementation. ISA Trans. 2021, 109, 296-306. [CrossRef] [PubMed]

18. Azzoug, Y.; Sahraoui, M.; Pusca, R.; Ameid, T.; Romary, R.; Cardoso, A.J.M. Current sensors fault detection and tolerant control strategy for three-phase induction motor drives. Electr. Eng. 2021, 103, 881-898. [CrossRef]

19. Adamczyk, M.; Orlowska-Kowalska, T. Post-Fault Direct Field-Oriented Control of Induction Motor Drive using Adaptive Virtual Current Sensor. IEEE Trans. Ind. Electron. 2021, in press. [CrossRef]

20. Orlowska-Kowalska, T. Sensoless Induction Motor Drives; Wroclaw University of Technology Press: Wroclaw, Poland, 2003.

21. Kubota, H.; Matsuse, K.; Nakano, T. DSP-based speed adaptive flux observer of induction motor. IEEE Trans. Ind. Appl. 1993, 29, 344-348. [CrossRef]

22. Orlowska-Kowalska, T.; Wojsznis, P.; Kowalski, C.T. Dynamical Performances of Sensorless Induction Motor Drive with Different Flux and Speed Observers. In Proceedings of the 9th European Conference on Power Electronics and Applications EPE'2001, Graz, Austria, 27-29 August 2001.

23. Adamczyk, M.; Orlowska-Kowalska, T. Current Sensors Fault Detection and Tolerant Control for Induction Motor Drive. In Proceedings of the IEEE 19th International Power Electronics and Motion Control Conference, PEMC 2021, Gliwice, Poland, 25-29 April 2021. 